\title{
Vancomycin Dosage and Its Association with Clinical Outcomes in Pediatric Patients with Gram-Positive Bacterial Infections
}

This article was published in the following Dove Press journal: Risk Management and Healthcare Policy

\author{
Sooyoung Shin $\mathbb{D}^{1,2}$ \\ Hyun Joo Jung ${ }^{3}$ \\ Sang-Min Jeon (iD) \\ Young-Joon Park' \\ Jung-Woo Chae $\mathbb{D}^{2}$ \\ Hwi-Yeol Yun (iD ${ }^{2}$ \\ 'College of Pharmacy, Ajou University, \\ Suwon, Gyeonggi-do 16499, Republic of \\ Korea; ${ }^{2}$ College of Pharmacy, Chungnam \\ National University, Daejeon 34I34, \\ Republic of Korea; ${ }^{3}$ Department of \\ Pediatrics, Ajou University Hospital, \\ Suwon, Gyeonggi-do 16499, Republic of \\ Korea
}

\begin{abstract}
Aim: The aim of this study was to evaluate whether vancomycin trough concentrations at initial steady state are associated with clinical and microbiological outcomes along with vancomycinrelated nephrotoxicity in pediatric patients with Gram-positive bacterial (GPB) infections.

Methods: A retrospective cohort study of pediatric patients who received vancomycin for $\geq 72$ hours during 2008-2016 was conducted. Study patients were divided into three cohorts in accordance with their first trough levels at steady state: $<5 \mathrm{mg} / \mathrm{L}$ (lower-trough), $5-10 \mathrm{mg} /$ L (low-trough), and $>10 \mathrm{mg} / \mathrm{L}$ (high-trough; reference) cohorts.
\end{abstract}

Results: Of the 201 patients eligible for study inclusion, 60 patients in the lower- and lowtrough cohorts, respectively, were idect 3 ntified via propensity score matching and analyzed against 30 high-trough patients in each comparison pair (neonates were excluded due to small sample size). Lower-trough patients were at a greater risk for prolonged therapy, retreatment, and dose adjustment than high-trough patients. Final steady-state troughs remained substantially lower in both the lower- and low-trough cohorts ( $p<0.001$ and $p=0.005$, respectively), despite greater dose up-titration in the lower-trough cohort and percent change in daily dose in both the lower- and low-trough cohorts than in the high-trough cohort ( $p<0.001$ for all). Clinical cure and death risk, along with the risks of isolation of resistant strains and renal events, were not significantly different between cohorts in both comparison pairs.

Conclusion: Vancomycin troughs of $<5 \mathrm{mg} / \mathrm{L}$ at initial steady state were associated with significantly compromised clinical outcomes in terms of risk of therapy prolongation, retreatment, and aggressive dose up-titration, compared to $>10 \mathrm{mg} / \mathrm{L}$ troughs in pediatric patients with GPB infections.

Keywords: pediatrics, vancomycin, drug monitoring, Gram-positive bacterial infection

\section{Introduction}

Vancomycin has been widely used since its introduction in clinical practice in the late 1950 s as a pivotal antibiotic to treat infections caused by a variety of Grampositive bacteria (GPB), especially those with penicillin-resistance properties. ${ }^{1}$ The vancomycin target troughs recommended by current guidelines on infectious diseases typically range from 10 to $20 \mathrm{mg} / \mathrm{L}$, but a higher-trough of 15 to $20 \mathrm{mg} / \mathrm{L}$ should be targeted for serious infections, such as meningitis, endocarditis, osteomyelitis, hospital-acquired pneumonia, and necrotizing fasciitis. ${ }^{2-4}$ The guidelines also suggest attaining a trough of $>10 \mathrm{mg} / \mathrm{L}$ to avoid the emergence of vancomycinresistant strains when treating GPB infections in general without accounting for the severity status of the disease in terms of complicatedness or invasiveness. ${ }^{2-5}$
Correspondence: Hwi-Yeol Yun; Jung-Woo Chae

Tel +8242 82I 594I; +824282I 5929

Fax +82428236566

Email hyyun@cnu.ac.kr;

jwchae@cnu.ac.kr 
Interestingly, a recent study in adult patients with non-deep seated GPB infections, treated with vancomycin for $\leq 14$ days, compared low-trough versus hightrough patients based on their initial-stage trough levels and found no difference in therapeutic effects as well as vancomycin resistance development risks between the two comparison groups. ${ }^{6}$ The findings indicate that therapeutic drug monitoring (TDM) services for vancomycin-treated inpatients and their required hospital resources could be allocated to more complicated cases in accordance with cost-effectiveness considerations, thereby relieving clinicians from some of the workload possibly associated with low patient benefits. Clinical evidence supporting the notion of achieving a hightrough in pediatric patients is sparse as they have often been excluded from clinical research. It is known that the serum concentration of vancomycin tends to be lower in pediatric patients than that in adult patients despite the administration of equivalent daily dose per patient weight, a trend likely attributable to differences in the vancomycin pharmacokinetic (PK) properties between pediatric and adult patients. ${ }^{7,8}$ This phenomenon leaves clinicians uncertain about optimal dosing and target troughs of vancomycin in this patient population. Some studies confirmed that vancomycin is frequently under-dosed, resulting in insufficient serum concentrations in pediatric patients, and suggested a higher empiric vancomycin dose of at least $50-60 \mathrm{mg} / \mathrm{kg} /$ day in critically ill children with no renal impairment ${ }^{9-11}$ or a loading dose of $18-24 \mathrm{mg} / \mathrm{kg}$ in case of positive fluid balance. ${ }^{12}$ Several other clinical studies also suggested a higher dose or an extended infusion of vancomycin in pediatric patients to improve target-attainment but without providing a dosing advice for these patients. ${ }^{13-17}$ A 2017 study, on the other hand, suggested a lower dose of $45 \mathrm{mg} / \mathrm{kg} /$ day in children with congenital heart disease. ${ }^{18}$ These studies were mostly not designed to provide evidence on whether suboptimal levels could lead to poor clinical outcomes in pediatric patients. Hence, there is a need to investigate the efficacy of current institutional dosing protocols of vancomycin in these patients taking into account the trough levels obtained by the protocols and their associated treatment outcomes in real-world clinical settings.

Accumulating evidence supports the efficacy of TDM based on the area under the concentration-time curve for 24 hours $\left(\mathrm{AUC}_{24}\right) \cdot{ }^{19-21}$ However, a more practical way of vancomycin TDM especially in pediatric care is still using trough levels because multiple blood samples per patient are required for monitoring $\mathrm{AUC}_{24}{ }^{22}$ Therefore, this study was designed to evaluate the therapeutic outcomes and resistance development risks along with potential renal toxicities of vancomycin therapy depending on initial steady-state trough levels among pediatric patients with GPB infections.

\section{Methods}

\section{Study Design and Cohort}

A retrospective cohort study of pediatric patients with GPB infections was carried out using patient data extracted from electronic medical records (EMRs) of a tertiary care hospital in Korea. All pediatric patients aged $\leq 12$ years who received vancomycin therapy between 2008 and 2016 were screened for study entry. Of those, patients who met any of the following criteria were excluded from the study: no trough levels recorded in EMRs, vancomycin therapy provided for $<72$ hours, no documented evidence of GPB-associated infections, prophylactic use of vancomycin, vancomycin-resistant enterococcus (VRE) infection cases, prior use of renal replacement therapy or dialysis, and history of renal transplantation or metastatic cancer. Selected patients were then categorized into three cohorts based on their initial trough levels: (1) those with a trough of $<5 \mathrm{mg} / \mathrm{L}$ (lower-trough group), (2) those with a trough of $5-10 \mathrm{mg} / \mathrm{L}$ (low-trough group), and (3) those with a trough of $>10 \mathrm{mg} / \mathrm{L}$ (high-trough group). The upper limit of the lower- and low-trough range was determined as $5 \mathrm{mg} / \mathrm{L}$ and $10 \mathrm{mg} / \mathrm{L}$, respectively, in consideration of distinct vancomycin PK differences and distribution patterns of initial troughs in pediatric patients. In light of current guidelines recommendation of achieving a trough of $>10 \mathrm{mg} / \mathrm{L}$ to hinder the microbiological resistance development, we designated the $>10 \mathrm{mg} / \mathrm{L}$ trough group as reference and designed two comparison pairs: lower-trough versus high-trough; lowtrough versus high-trough. It is still not known whether or not children need to achieve a trough over $15 \mathrm{mg} / \mathrm{L}$, based on PK data suggesting that the $\mathrm{AUC}_{24}$ values may be sufficient with lower-troughs. ${ }^{23}$ In this study, we were not able to answer such a question as our analysis did not include a separate group of $>15 \mathrm{mg} / \mathrm{L}$ trough values due to small sample size.

The empiric dosing protocols for pediatric patients at the study institution are as follows: $13.3-60 \mathrm{mg} / \mathrm{kg} /$ day according to body weight and postnatal age (PNA) in neonates, and $40-60 \mathrm{mg} / \mathrm{kg} / \mathrm{day}$ in older children; more detailed information can be found in supplementary material (Table S1). The Korean Food and Drug Administration (KFDA) recommendations range from 20 to $30 \mathrm{mg} / \mathrm{kg}$ /day 
according to PNA in neonates and from 20 to $40 \mathrm{mg} / \mathrm{kg}$ / day in older children. ${ }^{24}$ The first trough concentration at steady state was determined as follows: if dosing intervals were $\geq 12$ hours, the first trough measured one hour prior to the third or later dose; if dosing intervals were $\leq 8$ hours, the first trough measured 1 hour prior to the fourth or later dose. $^{6,8,25}$ Blood samples were analyzed by validated fluorescence polarimetry (Cobas Integra 800, Roche Diagnostics, Mannheim, Germany). The protocol of this study was approved by the Institutional Review Board of Ajou University Hospital (AJIRB-MED-MDB-17-137). Informed consent from study participants was waived due to the retrospective study design and patient data deidentification prior to study analyses.

\section{Study Outcomes}

The primary outcomes to evaluate the efficacy of vancomycin therapy included clinical cure (defined as no reinitiation of vancomycin administration within 30 days post completion of prior therapy and documented evidence of improvement in signs and symptoms or resolution of the disease), death, retreatment within 30 days after therapy completion, treatment duration, length of hospital stay, and final C-reactive protein (CRP) levels. As for microbiological outcomes, the risk of recurrent infections with incident vancomycin-resistant strains was assessed by identifying those cases where resistant GPB strains were newly isolated while on therapy or within 30 days after completion of prior therapy. Renal function of pediatric patients was estimated by using the revised Schwartz formula as follows: creatinine clearance $(\mathrm{CrCl})$ in $\mathrm{mL} / \mathrm{min}=$ $(0.413 \times \mathrm{Ht}) / \mathrm{SCr}$, where $\mathrm{Ht}$ denotes patient height in $\mathrm{cm}$ and $\mathrm{SCr}$ denotes serum creatinine in $\mathrm{mg} / \mathrm{dL}^{26}$ With respect to the secondary outcomes, information on final dosage and trough levels, dose adjustments over the course of therapy, and high-dose use ( $\geq 60 \mathrm{mg} / \mathrm{kg} /$ day) were also collected and compared between groups in each comparison pair. For renal safety analyses, newly diagnosed renal events during the follow-up, such as hypertensive renal disease, renal failure, nephritis syndrome, renal dialysis, and disorders due to impaired renal tubular function, along with any cases where SCr levels increased by $\geq 0.3 \mathrm{mg} / \mathrm{dL}$ or by $\geq 50 \%$ above baseline during the follow-up were identified to evaluate the potential nephrotoxic effects of vancomycin depending on trough concentrations at initial steady state. $^{27}$

\section{Covariates}

The prespecified covariates in this study were as follows: patient demographics (sex, age, and weight at baseline), location of hospitalization (intensive care unit [ICU] versus non-ICU), and days post hospitalization at vancomycin initiation, total daily doses, trough concentrations, comorbidities along with Charlson comorbidity index (CCI) scores, $\mathrm{SCr}$ and CRP values, concomitant medications (immunosuppressants, chemotherapies, nephrotoxins, and antimicrobials), infectious disease types, microbiological culture and susceptibility results, and isolation status of resistant GPB strains. Those patients transferred to ICUs within 48 hours following vancomycin initiation were categorized as ICU-hospitalized patients. Nephrotoxic drugs included nonsteroidal anti-inflammatory drugs, furosemide, hydralazine, aminoglycoside, contrast media, acyclovir, amphotericin, colistin, cyclosporine, and interferon.

\section{Statistical Analysis}

We investigated the association of suboptimal vancomycin levels in pediatric patients with clinical outcomes, relative to patients with therapeutic levels $(>10 \mathrm{mg} / \mathrm{L})$ at initial steady state. The multinomial propensity score (PS) for each patient was estimated by utilizing a logistic regression model accounting for relevant pretreatment attributes as covariates: age category, sex, CCI category, CRP category, ICU admission status, and infectious disease types to perform PS matching between each pair of comparison cohorts: lower-trough versus high-trough; low-trough versus high-trough. To control for potential confounders, each study cohort was matched in a 1:2 ratio based on the estimated PS, which predicts the probability of subtherapeutic trough (either lower- or low-trough) versus hightrough given the baseline covariates; separate PS matching was carried out in each of the two comparison pairs. We calculated crude odds ratios (ORs) with 95\% confidence intervals (CIs) for relevant clinical, microbiological, and renal safety outcomes associated with suboptimal versus $>10 \mathrm{mg} / \mathrm{L}$ trough levels in the initial stage of treatment in each comparison pair. To account for potential confounding factors, ORs and 95\% CIs were then adjusted for relevant pretreatment variables. The statistical analyses involving categorical variables were performed with the use of Chi-square or Fisher's exact tests, and for continuous variables, the $t$-test or the Wilcoxon rank-sum test was used to compare the difference between the two 
groups. $p$-values were two-tailed and deemed statistically significant if less than 0.05 . A literature review was conducted a priori to estimate the number of patients needed for the study analyses, but no relevant information on either cure or treatment failure rates specifically associated with pediatric GPB infection cases was available. ${ }^{28-30}$ Hence, all vancomycin-treated pediatric inpatients during the study period were screened, and only those found eligible based on the inclusion and exclusion criteria were finally included in this study. All statistical analyses were performed using SAS version 9.4 (SAS Institute Inc., Cary, NC, USA).

\section{Results}

\section{Characteristics of Study Patients}

During the 9-year study period, there were 908 pediatric patients who received at least one dose of vancomycin in the study institution, all of whom were initially screened for study entry. Following the screening, a total of 707 patients were excluded from further analyses due to the following reasons: no available trough values $(n=699$, which includes no documented evidence of GPB infections and prophylactic therapy); vancomycin therapy duration of $<72$ hours $(n=3)$; VRE infections $(n=4)$; and history of renal transplantation $(\mathrm{n}=1)$. Resultantly, 201 patients were finally considered eligible for study inclusion; of those, 87 patients with the first trough of $<5 \mathrm{mg} / \mathrm{L}$ were categorized as the lower-trough group and 82 with the first trough of $5-10 \mathrm{mg} / \mathrm{L}$ as the low-trough group, whereas the remaining 32 patients with the first trough of $>10 \mathrm{mg} / \mathrm{L}$ as the high-trough group. Notably, vancomycin trough levels in $169(84 \%)$ out of 201 pediatric patients were below the therapeutic target of $10 \mathrm{mg} / \mathrm{L}$. The mean age of initial cohorts prior to PS matching ranged from 3.7 to 4.4 years, and baseline attributes of those patients were summarized in Table S2 in the supplementary material.

Each of the lower-trough and low-trough cohorts were then matched on the PS to the high-trough cohort, respectively, for risk analyses of clinical outcomes of vancomycin treatment per initial trough levels. We incorporated the nearest neighbor matching method in order to allow for comparison between larger-sized matched groups: 60 patients in the lower- and low-trough cohorts, respectively, were identified via PS matching and analyzed against 30 high-trough patients in each comparison pair. Neonates were excluded prior to PS matching because there were only a small number of patients belonging to that age category. Overall, no significant between-group difference was found post PS matching in terms of most baseline attributes including sex, age, ICU versus nonICU hospitalization, comorbidity status, $\mathrm{SCr}$ values, infectious disease types, and isolation of resistant GPB strains, except for CRP values and concomitant antimicrobial use (Table 1). In both comparison pairs, the patient distribution differed substantially between groups with respect to the two variables (initial total daily doses and initial steady-state troughs), an inherent disparity owing to the design of this study as well as the classification criteria for each cohort. The high-trough group patients were initiated at a greater daily dose on average relative to the lower- and low-trough group patients: $55.6 \mathrm{mg} / \mathrm{kg} /$ day versus $41.0 \mathrm{mg} / \mathrm{kg} /$ day $(p<0.001)$ and $46.7 \mathrm{mg} / \mathrm{kg} / \mathrm{day}(p=0.01)$, respectively. Accordingly, the mean initial steady-state trough was $17.5 \mathrm{mg} / \mathrm{L}$ in the high-trough group, $7.0 \mathrm{mg} / \mathrm{L}$ in the low-trough group, and $3.2 \mathrm{mg} / \mathrm{L}$ in the lower-trough group. Baseline $\mathrm{SCr}$ values and CCI scores suggested normal renal function and minimal comorbidity burden at study entry in most study patients, respectively: the most common comorbid conditions involved pulmonary, circulatory, and genitourinary systems. There were seven oncology patients (three, three, and one in the lower-, low-, and high-trough cohorts, respectively) included in the PS-matched cohort analyses.

\section{Study Outcomes: Lower-Trough versus High-Trough Cohorts}

Table 2 summarizes the results of outcome analyses between the lower- and high-trough cohorts. ORs and 95\% CIs were adjusted for age category, CRP category, and concomitant antimicrobial use status at baseline. Poor clinical outcomes were indicated in the lower-trough group relative to the high-trough group in terms of 30day retreatment risk and overall treatment duration: lower-trough patients were more likely to be treated again within 30 days post therapy completion (adjusted $\mathrm{OR}=5.89, p=0.03)$; their mean duration of therapy tended to be longer ( 32.6 days versus 14.6 days, $p=0.01$ ) with an increased risk of treatment duration for $\geq 30$ days (adjusted OR 5.49, $p=0.01$ ). The ORs for cure and death, however, were not associated with a statistical significance, and Figure 1 also shows that there is no significant difference between groups in terms of cure and death risks. 
Table I Baseline Characteristics of Propensity Score-Matched Patient Cohorts in Two Comparison Pairs (Lower-Trough vs HighTrough; Low-Trough vs High-Trough)

\begin{tabular}{|c|c|c|c|c|c|}
\hline Variables & $\begin{array}{l}\text { Lower- } \\
\text { Trough } \\
(\mathrm{n}=60)\end{array}$ & $\begin{array}{l}\text { High-Trough } \\
\text { (Reference) }(n=30)\end{array}$ & $\begin{array}{l}\text { Low-Trough } \\
(\mathrm{n}=60)\end{array}$ & $\begin{array}{l}\text { p-value* Lower-Trough vs } \\
\text { High-Trough }\end{array}$ & $\begin{array}{l}\text { p-value* Low-Trough vs } \\
\text { High-Trough }\end{array}$ \\
\hline Sex (female), n (\%) & $23(38.3)$ & $9(30.0)$ & $18(30.0)$ & 0.44 & 1.00 \\
\hline $\begin{array}{l}\text { Age (years), mean } \pm S D \\
<1, \mathrm{n}(\%) \\
\mathrm{I}-12, \mathrm{n}(\%)\end{array}$ & $\begin{array}{l}3.6 \pm 3.7 \\
18(30.0) \\
42(70.0)\end{array}$ & $\begin{array}{l}3.9 \pm 4.3 \\
15(50.0) \\
15(50.0)\end{array}$ & $\begin{array}{l}4.2 \pm 4.1 \\
22(36.7) \\
38(63.3)\end{array}$ & $\begin{array}{l}0.74 \\
0.06\end{array}$ & $\begin{array}{l}0.74 \\
0.23\end{array}$ \\
\hline $\begin{array}{l}\text { ICU hospitalization at vancomycin } \\
\text { initiation, } \mathrm{n}(\%)\end{array}$ & $27(45.0)$ & $15(50.0)$ & $28(46.7)$ & 0.65 & 0.77 \\
\hline $\begin{array}{l}\text { Length of stay at vancomycin initiation } \\
\text { (days), mean } \pm S D\end{array}$ & $14.5 \pm 14.8$ & $12.4 \pm 19.1$ & $12.2 \pm 17.1$ & 0.57 & 0.96 \\
\hline $\begin{array}{l}\text { Initial total daily dose }(\mathrm{mg} / \mathrm{kg} / \mathrm{day}) \\
\text { mean } \pm S D\end{array}$ & $41.0 \pm 14.7$ & $55.6 \pm 16.1$ & $46.7 \pm 16.1$ & $<0.001$ & 0.01 \\
\hline $\begin{array}{l}\text { Comorbidity, } \mathrm{n}(\%) \\
\text { Pulmonary disease } \\
\text { Circulatory system disease } \\
\text { Genitourinary disease }\end{array}$ & $\begin{array}{l}24(40.0) \\
12(20.0) \\
8(13.3)\end{array}$ & $\begin{array}{l}14(46.7) \\
7(23.3) \\
5(16.7)\end{array}$ & $\begin{array}{l}34(56.7) \\
14(23.3) \\
7(11.7)\end{array}$ & 0.40 & 0.34 \\
\hline $\begin{array}{l}\mathrm{CCl} \text {, mean } \pm \mathrm{SD} \\
\leq \mathrm{I}, \mathrm{n}(\%) \\
2, \mathrm{n}(\%) \\
\geq 3, \mathrm{n}(\%)\end{array}$ & $\begin{array}{l}0.5 \pm 0.9 \\
51(85.0) \\
5(8.3) \\
4(6.7)\end{array}$ & $\begin{array}{l}0.4 \pm 0.8 \\
25(83.3) \\
5(16.7) \\
0(0.0)\end{array}$ & $\begin{array}{l}0.4 \pm 0.8 \\
53(88.3) \\
5(8.3) \\
2(3.3)\end{array}$ & $\begin{array}{l}0.80 \\
0.20\end{array}$ & $\begin{array}{l}0.79 \\
0.32\end{array}$ \\
\hline $\mathrm{SCr}(\mathrm{mg} / \mathrm{dL})$, mean $\pm \mathrm{SD}$ & $0.5 \pm 0.2$ & $0.6 \pm 0.9$ & $0.5 \pm 0.3$ & 0.13 & 0.43 \\
\hline $\mathrm{GRF}(\mathrm{mL} / \mathrm{min})$, mean $\pm \mathrm{SD}$ & $95.1 \pm 37.0$ & $90.3 \pm 44.1$ & $90.9 \pm 41.8$ & 0.64 & 0.96 \\
\hline CRP $(\mathrm{mg} / \mathrm{dL})$, mean $\pm \mathrm{SD}$ & $4.0 \pm 5.5$ & $8.4 \pm 9.6$ & $5.8 \pm 8.3$ & 0.007 & 0.18 \\
\hline $\begin{array}{l}\text { Concomitant immunosuppressant or } \\
\text { chemotherapy, n (\%) }\end{array}$ & $4(6.7)$ & I (3.3) & $\mathrm{I}(1.7)$ & 0.52 & 0.61 \\
\hline $\begin{array}{l}\text { Concomitant nephrotoxin, n (\%) } \\
\text { Number of concomitant } \\
\text { nephrotoxins, median (IQR) }\end{array}$ & $\begin{array}{l}48(80.0) \\
I(I-2)\end{array}$ & $\begin{array}{l}26(86.7) \\
2(1-2)\end{array}$ & $\begin{array}{l}51(85.0) \\
2(1-2)\end{array}$ & $\begin{array}{l}0.44 \\
0.10\end{array}$ & $\begin{array}{l}0.83 \\
0.69\end{array}$ \\
\hline Concomitant antimicrobial, n (\%) & $39(65.0)$ & $28(93.3)$ & $46(76.7)$ & 0.004 & 0.05 \\
\hline $\begin{array}{l}\text { Infectious disease types, } \mathrm{n}(\%) \\
\text { Skin and soft tissue infection } \\
\text { Urinary tract infection } \\
\text { Pneumonia } \\
\text { Bacteremia }\end{array}$ & $\begin{array}{l}13(21.7) \\
8(13.3) \\
16(26.7) \\
10(16.7)\end{array}$ & $\begin{array}{l}2(6.7) \\
3(10.0) \\
13(43.3) \\
9(30.0)\end{array}$ & $\begin{array}{l}7(11.7) \\
9(15.0) \\
14(23.3) \\
14(23.3)\end{array}$ & 0.29 & 0.26 \\
\hline $\begin{array}{l}\text { Resistant Gram-positive isolates, } n \text { (\%) } \\
\text { MRSA } \\
\text { CoNS }\end{array}$ & $\begin{array}{l}29(48.3) \\
19(31.7) \\
16(26.7)\end{array}$ & $\begin{array}{l}15(50.0) \\
12(40.0) \\
4(13.3)\end{array}$ & $\begin{array}{l}24(40.0) \\
16(26.7) \\
14(23.3)\end{array}$ & 0.88 & 0.37 \\
\hline $\begin{array}{l}\text { Initial steady-state trough }(\mathrm{mg} / \mathrm{L}), \text { mean } \pm S D \\
<1 \text { year } \\
1-12 \text { years }\end{array}$ & $\begin{array}{l}3.2 \pm 1.0 \\
3.4 \pm 1.2 \\
3.1 \pm 1.0\end{array}$ & $\begin{array}{l}17.5 \pm 7.7 \\
15.3 \pm 4.3 \\
19.7 \pm 9.7\end{array}$ & $\begin{array}{l}7.0 \pm 1.4 \\
7.4 \pm 1.5 \\
6.9 \pm 1.3\end{array}$ & $\begin{array}{l}<0.001 \\
<0.001 \\
<0.001\end{array}$ & $\begin{array}{l}<0.001 \\
<0.001 \\
<0.001\end{array}$ \\
\hline
\end{tabular}

Notes: *p-values were calculated with the use of Chi-square test (Fisher's exact test) for categorical variables and t-test (Wilcoxon rank-sum test) for continuous variables. Statistically significant $p$-values are highlighted in bold. Renal function of pediatric patients was estimated by using the revised Schwartz formula as follows: creatinine clearance $(\mathrm{CrCl})$ in $\mathrm{mL} / \mathrm{min}=(0.413 \times \mathrm{Ht}) / \mathrm{SCr}$, where $\mathrm{Ht}$ denotes patient height in $\mathrm{cm}$ and $\mathrm{SCr}$ denotes serum $\mathrm{creatinine}$ in $\mathrm{mg} / \mathrm{dL}$. ${ }^{26}$

Abbreviations: SD, standard deviation; ICU, intensive care unit; IQR, interquartile range; CCl, Charlson comorbidity index; SCr, serum creatinine; GFR, glomerular filtration rate; CRP, C-reactive protein; MRSA, methicillin-resistant Staphylococcus aureus; CoNS, coagulase-negative Staphylococcus. 
Table 2 Study Outcomes in Propensity Score-Matched Patients of Lower-Trough versus High-Trough Cohorts

\begin{tabular}{|c|c|c|c|c|c|c|}
\hline Outcomes & $\begin{array}{l}\text { Lower-trough } \\
(n=60)\end{array}$ & $\begin{array}{l}\text { High-trough } \\
(n=30)\end{array}$ & $\begin{array}{l}\text { Crude OR } \\
(95 \% \mathrm{Cl})\end{array}$ & $p$-value & $\begin{array}{l}\text { Adjusted OR } \\
(95 \% \mathrm{Cl})^{*}\end{array}$ & p-value \\
\hline \multicolumn{7}{|l|}{ Clinical outcome } \\
\hline Clinical cure, n (\%) & $38(63.3)$ & $24(80.0)$ & $0.43(0.15-1.22)$ & 0.11 & $0.43(0.14-1.32)$ & 0.14 \\
\hline Death, n (\%) & $4(6.7)$ & $4(13.3)$ & $0.46(0.11-2.00)$ & 0.29 & $0.38(0.07-1.95)$ & 0.24 \\
\hline Final CRP $(\mathrm{mg} / \mathrm{dL})$, mean $\pm S D$ & $2.7 \pm 6.2$ & $3.0 \pm 3.6$ & & 0.85 & & \\
\hline Therapy duration (days), mean $\pm S D$ & $32.6 \pm 37.6$ & $14.6 \pm 9.9$ & & 0.01 & & 0.01 \\
\hline$\geq 30$ days, $\mathrm{n}(\%)$ & $21(35.0)$ & $3(10.0)$ & $4.85(1.31-17.88)$ & 0.01 & $5.49(1.39-21.62)$ & 0.01 \\
\hline Length of hospital stay (days), mean $\pm S D$ & $72.6 \pm 96.5$ & $72.0 \pm 140.5$ & & 0.98 & & \\
\hline Retreatment within 30 days, $\mathrm{n} /$ survivors (\%) & $18 / 56(32.1)$ & $2 / 26(7.7)$ & $5.68(1.21-26.72)$ & 0.02 & $5.89(1.24-29.22)$ & 0.03 \\
\hline \multicolumn{7}{|l|}{ Microbiological outcome } \\
\hline $\begin{array}{l}\text { Resistant Gram + isolates identified } \\
\text { while on therapy or within } 30 \text { days after } \\
\text { vancomycin discontinuation, n/survivors (\%) }\end{array}$ & $4 / 56(7.1)$ & $2 / 26(7.7)$ & $0.92(0.16-5.39)$ & 0.93 & $1.30(0.21-8.18)$ & 0.78 \\
\hline \multicolumn{7}{|l|}{ Vancomycin dose and trough } \\
\hline Final total daily dose ( $\mathrm{mg} / \mathrm{kg} / \mathrm{day})$, mean $\pm \mathrm{SD}$ & $48.0 \pm 18.6$ & $49.8 \pm 13.4$ & & 0.67 & & \\
\hline$\%$ change in total daily dose (\%), mean \pm SD & $17.6 \pm 25.0$ & $-9.0 \pm 21.3$ & & $<0.001$ & & \\
\hline Number of patients with daily dose $\geq 60 \mathrm{mg} / \mathrm{kg} / \mathrm{day}, \mathrm{n}$ (\%) & $10(21.7)$ & $12(48.0)$ & $0.30(0.11-0.86)$ & 0.02 & $0.38(0.12-1.23)$ & 0.11 \\
\hline Final steady-state trough $(\mathrm{mg} / \mathrm{L})$, mean $\pm \mathrm{SD}$ & $5.3 \pm 3.3$ & $14.4 \pm 7.9$ & & $<0.001$ & & \\
\hline$\%$ change in trough $(\%)$, mean $\pm S D$ & $87.8 \pm 126.7$ & $-13.0 \pm 25.8$ & & $<0.001$ & & \\
\hline Number of patients requiring dose adjustment, $n$ (\%) & $45(75.0)$ & $10(33.3)$ & $6.00(2.30-15.64)$ & $<0.001$ & $9.06(3.03-27.12)$ & $<0.001$ \\
\hline Number of dose adjustments per patient, mean $\pm \mathrm{SD}$ & $1.9 \pm 1.8$ & $0.6 \pm 1.2$ & & 0.001 & & \\
\hline \multicolumn{7}{|l|}{ Renal function outcome } \\
\hline Final $\mathrm{SCr}(\mathrm{mg} / \mathrm{dL})$, mean $\pm \mathrm{SD}$ & $0.4 \pm 0.1$ & $0.6 \pm 1.1$ & & 0.06 & & \\
\hline GFR (mL/min), mean $\pm \mathrm{SD}$ & $112.4 \pm 42.9$ & $95.8 \pm 52.3$ & & 0.17 & & \\
\hline Renal event, n (\%) & $2(3.3)$ & $3(10.0)$ & $0.31(0.05-1.97)$ & 0.19 & $0.25(0.04-1.82)$ & 0.17 \\
\hline
\end{tabular}

Notes: *ORs and $95 \%$ Cls were adjusted for age category, initial CRP category, and concomitant antimicrobial use. $p$-values were calculated with the use of Chi-square test (Fisher's exact test) for categorical variables and $t$-test (Wilcoxon rank-sum test) for continuous variables. Statistically significant $p$-values are highlighted in bold. Renal function of pediatric patients was estimated by using the revised Schwartz formula as follows: creatinine clearance $(\mathrm{CrCl}) \mathrm{in} \mathrm{mL} / \mathrm{min}=(0.4 \mathrm{I} 3 \times \mathrm{Ht}) / \mathrm{SCr}$, where $\mathrm{Ht}$ denotes patient height in $\mathrm{cm}$ and $\mathrm{SCr}$ denotes serum creatinine in $\mathrm{mg} / \mathrm{dL}^{26}$

Abbreviations: OR, odds ratio; $\mathrm{Cl}$, confidence interval; SD, standard deviation; IQR, interquartile range; CRP, C-reactive protein; SCr, serum creatinine; GFR, glomerular filtration rate.

Although patients in the lower-trough group started with a substantially smaller dose at therapy initiation, their doses were titrated up to a greater extent over the course of therapy such that the between-group difference in the mean total daily dose at therapy completion was significantly reduced (Table 2). Of note is that, despite the substantial dose adjustments in the lower-trough group patients, their trough levels at therapy completion remained significantly lower than those in the high-trough group: the mean value for the final troughs was $5.3 \mathrm{mg} / \mathrm{L}$ versus $14.4 \mathrm{mg} / \mathrm{L}(p<0.001)$. Early discontinuation of therapy before blood sampling or before reaching steady state post dose adjustment, suboptimal adherence to TDM guidelines or unconsulted patients, and greater variability in vancomycin half-life and less intensive blood sampling in pediatric patients than in adults may all have contributed to these observations.

Overall, the mean length of hospital stay was not statistically different between the two groups: 72.6 days versus 72.0 days in the lower- and high-trough groups, respectively $(p=0.98)$. Also, the distribution of final CRP values appeared balanced between groups: the mean value was $2.7 \mathrm{mg} / \mathrm{dL}$ and $3.0 \mathrm{mg} / \mathrm{dL}$ in the lower- and high-trough groups, respectively ( $p=0.85$ ). Regarding vancomycin-resistant GPB isolation and nephrotoxicity risks, no signal of significant resistance development or renal function impairment was detected in both groups throughout the follow-up.

\section{Study Outcomes: Low-Trough versus High-Trough Cohorts}

Similar analyses were repeated in low-trough versus hightrough patients to better evaluate the differential effects of vancomycin treatment depending on initial trough levels on clinical outcomes, using analogous PS matching methods utilized in the previous outcome analyses. The results are summarized in Table 3. The cure rates approached $80 \%$ (72/90) in overall patients as well as in each patient group. Most ORs for individual clinical outcomes, including 30-day retreatment and overall therapy duration, were not associated with a statistical 


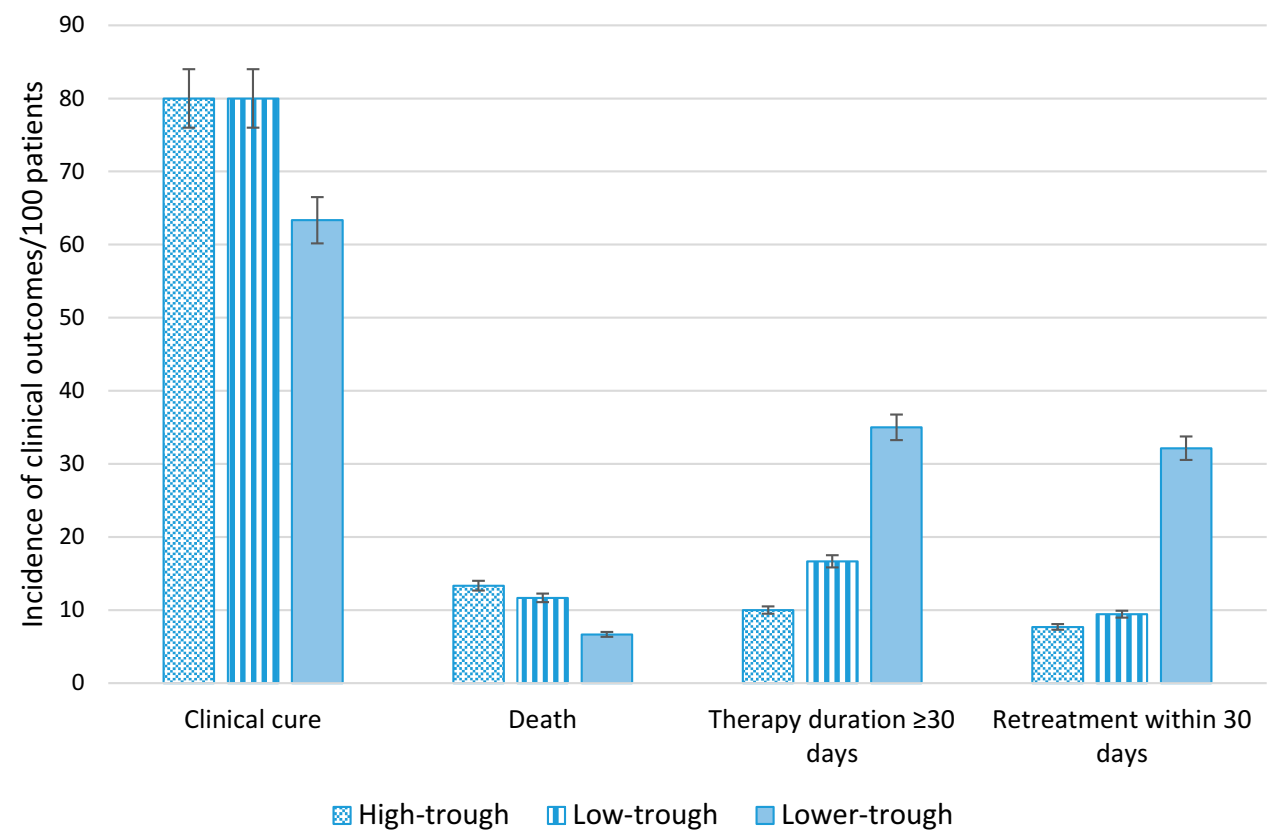

Figure I Clinical outcomes for the propensity score-matched comparison groups.

significance except for percent change in total daily doses and final steady-state troughs along with percent change in trough levels. A similar pattern was observed in the microbiological outcome and renal safety analyses: the ORs of vancomycinresistant GPB isolation and renal events were not assessed as statistically significant.

\section{Discussion}

Amid growing concerns over antibiotic resistance worldwide, it becomes of paramount importance to treat infectious diseases in a way that is safe for patients and effective at preventing the rise of resistant organisms. One strategy to overcome constantly-evolving microbial species is to achieve vancomycin troughs within the therapeutic index at least in 24 hours post therapy initiation as endorsed by current guidelines. ${ }^{31-33}$ Interestingly, however, in 169 (84\%) out of 201 patients included in the initial study cohort, the first trough at steady state did not reach $10 \mathrm{mg} / \mathrm{L}$, the lower limit of the therapeutic range that guidelines recommend to suppress the emergence of resistant GPB strains, and only $32(16 \%)$ patients attained the first trough of above $10 \mathrm{mg} / \mathrm{L}$ (Table S2). More notably, in almost 43\% of study patients (87 in 201 patients), below $5 \mathrm{mg} / \mathrm{L}$ troughs were recorded at initial steady state.

This positively shewed distribution of trough concentrations is likely attributed to differences in vancomycin PKs in pediatric patients. It is well documented that, in accordance with the degree of physiological development and maturation, pediatric patients have a greater vancomycin clearance and resultantly a shorter half-life as compared to adult patients. ${ }^{7,8}$ Hence, when equivalent amounts of vancomycin per patient weight are administered to pediatric patients, their serum concentrations tend to be lower than those in adult patients. Additionally, in pediatric patients, over $60 \%$ of the body composition is water, ${ }^{34-36}$ which dilutes vancomycin concentrations. Due to differences in the volume of distribution and high $\mathrm{CrCl}$ in pediatrics, relationships between trough concentrations and AUC might be different than in adults, and therefore might influence the relationship between trough levels and outcomes. $^{34-36}$

Of note was that the clinical outcomes significantly associated with the differential trough levels at initial steady state were the risks of long-term therapy, retreatment, and frequent dose adjustments that were substantially elevated in the lowertrough group with $<5 \mathrm{mg} / \mathrm{L}$ levels. Meanwhile, the study findings showed no statistically significant improvement in other clinical and microbiological outcomes (cure, death, length of hospital stay, resistant GPB isolation, and adverse renal events) with high-troughs at initial steady state compared to $<5 \mathrm{mg} / \mathrm{L}$ troughs. These non-significant results in clinical efficacy might have been affected not only by the limited number of study patients and low statistical power but also by commonly insufficient vancomycin exposure and different vancomycin PKs in pediatric patients. According to current TDM guidelines, adequate antibiotic efficacy is achieved when 
Table 3 Study Outcomes in Propensity Score-Matched Patients of Low-Trough versus High-Trough Cohorts

\begin{tabular}{|c|c|c|c|c|c|c|}
\hline Outcomes & $\begin{array}{l}\text { Low- } \\
\text { Trough } \\
(n=60)\end{array}$ & $\begin{array}{l}\text { High- } \\
\text { Trough } \\
(n=30)\end{array}$ & $\begin{array}{l}\text { Crude OR } \\
(95 \% \mathrm{Cl})\end{array}$ & p-value & $\begin{array}{l}\text { Adjusted OR } \\
(95 \% \mathrm{CI})^{*}\end{array}$ & p-value \\
\hline \multicolumn{7}{|l|}{ Clinical outcome } \\
\hline Clinical cure, $n(\%)$ & $48(80.0)$ & $24(80.0)$ & $1.00(0.33-2.99)$ & 1.00 & I.3I (0.40-4.29) & 0.65 \\
\hline Death, n (\%) & 7 (II.7) & $4(13.3)$ & $0.86(0.23-3.20)$ & 0.82 & $0.43(0.09-1.99)$ & 0.28 \\
\hline Final CRP $(\mathrm{mg} / \mathrm{dL})$, mean $\pm \mathrm{SD}$ & $2.9 \pm 5.7$ & $3.0 \pm 3.6$ & & 0.93 & & \\
\hline Therapy duration (days), mean $\pm S D$ & $19.0 \pm 12.1$ & $14.6 \pm 9.9$ & & 0.09 & & \\
\hline$\geq 30$ days, $\mathrm{n}(\%)$ & $10(16.7)$ & $3(10.0)$ & $1.80(0.46-7.10)$ & 0.40 & $2.54(0.62-10.48)$ & 0.20 \\
\hline Length of hospital stay (days), mean \pm SD & $54.0 \pm 70.0$ & $72.0 \pm 140.5$ & & 0.42 & & \\
\hline Retreatment within 30 days, $\mathrm{n} /$ survivors (\%) & $5 / 53(9.4)$ & $2 / 26(7.7)$ & $1.25(0.23-6.92)$ & 0.80 & $1.60(0.28-9.10)$ & 0.60 \\
\hline \multicolumn{7}{|l|}{ Microbiological outcome } \\
\hline $\begin{array}{l}\text { Resistant Gram + isolates identified while on } \\
\text { therapy or within } 30 \text { days after vancomycin } \\
\text { discontinuation, } n \text { /survivors (\%) }\end{array}$ & $4 / 53(7.5)$ & $2 / 26(7.7)$ & $0.98(0.17-5.73)$ & 0.98 & $1.19(0.19-7.24)$ & 0.85 \\
\hline \multicolumn{7}{|l|}{ Vancomycin dose and trough } \\
\hline Final total daily dose $(\mathrm{mg} / \mathrm{kg} /$ day $)$, mean $\pm \mathrm{SD}$ & $50.9 \pm 16.0$ & $49.8 \pm 13.4$ & & 0.78 & & \\
\hline$\%$ Change in total daily dose (\%), mean \pm SD & $10.6 \pm 22.7$ & $-9.0 \pm 21.3$ & & $<0.001$ & & \\
\hline Number of patients with daily dose $\geq 60$ mg/kg/day, $\mathrm{n}$ (\%) & $12(25.5)$ & $12(48.0)$ & $0.37(0.13-1.03)$ & 0.05 & $0.45(0.15-1.37)$ & 0.16 \\
\hline Final steady-state trough $(\mathrm{mg} / \mathrm{L})$, mean $\pm \mathrm{SD}$ & $10.1 \pm 6.2$ & $14.4 \pm 7.9$ & & 0.005 & & \\
\hline$\%$ Change in trough (\%), mean \pm SD & $34.3 \pm 71.4$ & $-13.0 \pm 25.8$ & & 0.002 & & \\
\hline Number of patients requiring dose adjustment, $\mathrm{n}(\%)$ & $15(25.0)$ & $10(33.3)$ & $0.67(0.26-1.74)$ & 0.41 & $0.87(0.32-2.42)$ & 0.79 \\
\hline Number of dose adjustments per patient, mean $\pm S D$ & $0.5 \pm 1.3$ & $0.6 \pm 1.2$ & & 0.69 & & \\
\hline \multicolumn{7}{|l|}{ Renal function outcome } \\
\hline Final SCr (mg/dL), mean \pm SD & $0.5 \pm 0.5$ & $0.6 \pm 1.1$ & & 0.35 & & \\
\hline $\mathrm{GFR}(\mathrm{mL} / \mathrm{min})$, mean $\pm \mathrm{SD}$ & $108.3 \pm 54.6$ & $95.8 \pm 52.3$ & & 0.36 & & \\
\hline Renal event, n (\%) & $3(5.0)$ & $3(10.0)$ & $0.47(0.09-2.50)$ & 0.37 & $0.37(0.06-2.20)$ & 0.28 \\
\hline
\end{tabular}

Notes: *ORs and $95 \% \mathrm{Cls}$ were adjusted for age category, initial CRP category, and concomitant antimicrobial use. $p$-values were calculated with the use of Chi-square test (Fisher's exact test) for categorical variables and t-test (Wilcoxon rank-sum test) for continuous variables. Statistically significant $p$-values are highlighted in bold. Renal function of pediatric patients was estimated by using the revised Schwartz formula as follows: creatinine clearance $(\mathrm{CrCl})$ in $\mathrm{mL} / \mathrm{min}=(0.4 \mathrm{I} 3 \times \mathrm{Ht}) / \mathrm{SCr}$, where $\mathrm{Ht}$ denotes patient height in $\mathrm{cm}$ and $\mathrm{SCr}$ denotes serum creatinine in $\mathrm{mg} / \mathrm{dL}^{26}$

Abbreviations: OR, odds ratio; $\mathrm{Cl}$, confidence interval; SD, standard deviation; IQR, interquartile range; CRP, C-reactive protein; SCr, serum creatinine; GFR, glomerular filtration rate.

a vancomycin $\mathrm{AUC}_{24}$ divided by the minimum inhibitory concentration (MIC) is $\geq 400$. $^{2,37}$ However, the $\mathrm{AUC}_{24}$-based TDM is not practical in pediatric care units as it requires multiple blood draws per patient. ${ }^{22}$ Further research with a larger sample size may show a statistically significant association between these outcomes with the attainment of troughs of $>10 \mathrm{mg} / \mathrm{L}$ at initial steady state in the context of achieving the $\mathrm{AUC}_{24} / \mathrm{MIC}$ target of $\geq 400$.

In consideration of vancomycin PK characteristics and body composition differences in pediatric patients, ${ }^{7,8,34-36}$ aiming for a higher-trough at initial steady state can be beneficial for disease management of pediatric infectious disease cases requiring vancomycin therapy, particularly by reducing the risk of treatment prolongation and recurrent infection as well as the need for frequent TDM-guided dose adjustment. Due to the narrow therapeutic index, TDM services are commonly provided for vancomycin-treated patients in the hospital. $^{2-5}$ A previous study questioned the need of keeping vancomycin troughs above $10 \mathrm{mg} / \mathrm{L}$ in adult patients with infections, treated for short term ( $\leq 14$ days): targeting a trough of $>10 \mathrm{mg} / \mathrm{L}$ led to greater clinician workload (the time required per dose adjustment was estimated as 53 minutes) but without corresponding gains regarding clinical response and resistance suppression. ${ }^{6}$ Uncertainty remained about whether such findings could be applied to pediatric patients. The present study in pediatric patients found that almost $84 \%$ and $43 \%$ of study patients had the first trough of $<10 \mathrm{mg} / \mathrm{L}$ and $<5 \mathrm{mg} / \mathrm{L}$ at steady state, respectively, and that $<5 \mathrm{mg} / \mathrm{L}$ trough patients were at an elevated risk for poorer clinical outcomes than $>10 \mathrm{mg} / \mathrm{L}$ trough patients in terms of therapy duration, retreatment, and dose adjustment risks. To the best of our knowledge, these differential clinical outcomes 
depending on the first trough levels have never been reported in previous studies. Meanwhile, there was no difference between 5-10 mg/L and $>10 \mathrm{mg} / \mathrm{L}$ troughs in the aforementioned clinical outcomes; further research with statistical power is required to answer the question of whether or not below $10 \mathrm{mg} / \mathrm{L}$ troughs may be sufficient to achieve equivalent clinical outcomes compared with $>10 \mathrm{mg} / \mathrm{L}$ troughs in pediatric patients.

The current dosing guidelines, in general, provide a wide range for empiric pediatric dosages, which typically range from 15 to $45 \mathrm{mg} / \mathrm{kg} /$ day in neonates and from 30 to $80 \mathrm{mg}$ / $\mathrm{kg} /$ day in older children. ${ }^{5,11,38}$ The wide range may leave clinicians uncertain about the optimal dosage for individual patients. In order to reduce the risk of belated dose adjustments and delay in therapeutic effects, pediatric patients may benefit from receiving a higher dose in the initial stage of treatment. Based on our study findings, approximately $55 \mathrm{mg} / \mathrm{kg} /$ day in children aged 1 month to 12 years could increase the chance of attaining the initial trough of $>10 \mathrm{mg} / \mathrm{L}$. Despite the 2009 Infectious Diseases Society of American updates with regard to targeting a higher-trough range to improve clinical outcomes, empiric dosing protocols have not been revised accordingly to reflect the changes and ensure sufficient drug exposure in pediatric patients. As a result, insufficient vancomycin dosages and suboptimal trough levels have been frequently encountered among pediatric patients in real-world practice. Our findings regarding a high incidence of subtherapeutic levels in children are consistent with the data in previous studies that reported the issue of insufficient doses of vancomycin commonly administered to pediatric patients ${ }^{9-17}$ and that also suggested a higher empiric dose of at least 50-60 mg/ $\mathrm{kg} /$ day in children with no renal impairment. ${ }^{9-11}$

\section{Limitations}

Due to the single-institution study design with the strict eligibility criteria for study inclusion and the availability of trough concentrations in EMRs, the total number of patients included in this study was limited. The first troughs at steady state in the majority of pediatric patients were relatively lower than those reported in a previous study involving adult patients. The rightskewed distribution of initial troughs might have been inevitable due to vancomycin PKs and physiological characteristics in pediatric patients. Additionally, there was a great degree of variations in vancomycin regimens for individual patients. It was possible that individual prescribers may not have strictly adhered to the institutional empiric dosing guidelines when selecting starting doses for pediatric patients. TDM and dose adjustments may not have been properly performed in some unconsulted patients or those patients cared in other departments, whose vancomycin therapy has not been managed by infectious disease specialists or TDM pharmacists. Lastly, although the first troughs at steady state were captured for study analyses, the conditions for collecting blood samples to measure vancomycin concentrations might not have been comparable in each patient.

\section{Conclusion}

This study found significant link between vancomycin troughs of $<5 \mathrm{mg} / \mathrm{L}$ at initial steady state and poor clinical outcomes, such as risks of therapy prolongation, retreatment, and frequent dose adjustment, relative to $>10 \mathrm{mg} / \mathrm{L}$ troughs in pediatric patients with GPB infections. Patients with $<5 \mathrm{mg} / \mathrm{L}$ troughs at initial steady state were more likely to require aggressive dose up-titration over the course of therapy, which could increase clinician workload and cause delay in therapy. In light of distinct vancomycin pharmacokinetics and body composition differences in pediatric patients, empiric doses of about $55 \mathrm{mg} / \mathrm{kg} /$ day should be considered when selecting a pediatric dose for children aged between 1 month and 12 years.

\section{Acknowledgments}

This study was supported by Basic Science Research Program through the National Research Foundation of Korea (NRF) funded by the Ministry of Science, ICT \& Future Planning (No. 2017R1C1B5015912) and by Ajou University research fund (S-2016-G0001-00335).

\section{Disclosure}

The authors confirm that the Principal Investigators for this paper are Hwi-Yeol Yun and Jung-Woo Chae. The authors report no conflicts of interest in this research.

\section{References}

1. Levine DP. Vancomycin: a history. Clin Infect Dis. 2006;42(Suppl 1): S5-S12. doi:10.1086/491709

2. Rybak M, Lomaestro B, Rotschafer JC, et al. Therapeutic monitoring of vancomycin in adult patients: a consensus review of the American Society of Health-System Pharmacists, the Infectious Diseases Society of America, and the Society of Infectious Diseases Pharmacists. Am J Health Syst Pharm. 2009;66(1):82-98. doi:10.2146/ajhp080434

3. Matsumoto K, Takesue Y, Ohmagari N, et al. Practice guidelines for therapeutic drug monitoring of vancomycin: a consensus review of the Japanese Society of Chemotherapy and the Japanese Society of Therapeutic Drug Monitoring. J Infect Chemother. 2013;19 (3):365-380. doi:10.1007/s10156-013-0599-4

4. Ye ZK, Chen YL, Chen K, et al. Therapeutic drug monitoring of vancomycin: a guideline of the Division of Therapeutic Drug Monitoring, Chinese Pharmacological Society. J Antimicrob Chemother. 2016;71(11):3020-3025. doi:10.1093/jac/dkw254 
5. Liu C, Bayer A, Cosgrove SE, et al. Clinical practice guidelines by the infectious diseases society of America for the treatment of methicillin-resistant Staphylococcus aureus infections in adults and children: executive summary. Clin Infect Dis. 2011;52(3):285-292. doi:10.1093/cid/cir034

6. Wan M, Walker SAN, Martin E, et al. The impact of vancomycin trough concentrations on outcomes in non-deep seated infections: a retrospective cohort study. BMC Pharmacol Toxicol. 2018;19 (1):47. doi:10.1186/s40360-018-0236-Z

7. Durham SH, Simmons ML, Mulherin DW, et al. An evaluation of vancomycin dosing for complicated infections in pediatric patients. Hosp Pediatr. 2015;5(5):276-281. doi:10.1542/hpeds.2014-0081

8. Rybak MJ. The pharmacokinetic and pharmacodynamic properties of vancomycin. Clin Infect Dis. 2006;42(Suppl 1):S35-S39. doi: $10.1086 / 491712$

9. Sosnin N, Curtis N, Cranswick N, et al. Vancomycin is commonly under-dosed in critically ill children and neonates. $\mathrm{Br} J$ Clin Pharmacol. 2019;85(11):2591-2598. doi:10.1111/bcp.14084

10. Glover ML, Cole E, Wolfsdorf J. Vancomycin dosage requirements among pediatric intensive care unit patients with normal renal function. $J$ Crit Care. 2000;15(1):1-4. doi:10.1053/jcrc.2000.0150001

11. Moffett BS, Resendiz K, Morris J, et al. Population pharmacokinetics of vancomycin in the pediatric cardiac surgical population. $J$ Pediatr Pharmacol Ther. 2019;24(2):107-116. doi:10.5863/1551-6776-24.2.107

12. Giachetto GA, Telechea HM, Speranza N, et al. Vancomycin pharmacokinetic-pharmacodynamic parameters to optimize dosage administration in critically ill children. Pediatr Crit Care Med. 2011;12(6):e250-e254. doi:10.1097/PCC.0b013e3181fe4047

13. Avedissian SN, Bradley E, Zhang D, et al. Augmented renal clearance using population-based pharmacokinetic modeling in critically ill pediatric patients. Pediatr Crit Care Med. 2017;18(9):e388-e394. doi:10.1097/PCC.0000000000001228

14. Genuini M, Oualha M, Bouazza N, et al. Achievement of therapeutic vancomycin exposure with continuous infusion in critically ill children. Pediatr Crit Care Med. 2018;19(6):e263-e269. doi:10.1097/PCC.0000000000001474

15. Gous AG, Dance MD, Lipman J, et al. Changes in vancomycin pharmacokinetics in critically ill infants. Anaesth Intensive Care. 1995;23(6):678-682. doi:10.1177/0310057X9502300603

16. Seixas GT, Araujo OR, Silva DC, et al. Vancomycin therapeutic targets and nephrotoxicity in critically ill children with cancer. $J$ Pediatr Hematol Oncol. 2016;38(2):e56-e62. doi:10.1097/ MPH.0000000000000470

17. Silva DC, Seixas GT, Araujo OR, et al. Vancomycin serum concentrations in pediatric oncologic/hematologic intensive care patients. Braz J Infect Dis. 2012;16(4):361-365. doi:10.1016/j. bjid.2012.06.011

18. Thomas CA, Picone A, Menon S, et al. Empirical vancomycin dosing in pediatric patients with congenital heart disease and the impact of cardiopulmonary bypass on trough concentrations. Pharmacotherapy. 2017;37(11):1341-1346. doi:10.1002/phar.2019

19. Janssen EJ, Välitalo PA, Allegaert K, et al. Towards rational dosing algorithms for vancomycin in neonates and infants based on population pharmacokinetic modeling. Antimicrob Agents Chemother. 2015;60(2):1013-1021. doi:10.1128/AAC.01968-15

20. Biagi MJ, Butler DA, Wenzler E. AUC-based monitoring of vancomycin: closing the therapeutic window. J Appl Lab Med. 2019;3 (4):743-746. doi:10.1373/jalm.2018.027391

21. Tseng SH, Lim CP, Chen Q, et al. Evaluating the relationship between vancomycin trough concentration and 24-hour area under the concentration-time curve in neonates. Antimicrob Agents Chemother. 2018;62(4):e01647-17. doi:10.1128/AAC.01647-17
22. Heil EL, Claeys KC, Mynatt RP, et al. Making the change to area under the curve-based vancomycin dosing. Am J Health Syst Pharm. 2018;75(24):1986-1995. doi:10.2146/ajhp180034

23. Kishk OA, Lardieri AB, Heil EL, et al. Vancomycin AUC/MIC and corresponding troughs in a pediatric population. J Pediatr Pharmacol Ther. 2017;22(1):41-47. doi:10.5863/1551-6776-22.1.41

24. Pediatric Dosing Recommendations. Korean Food and Drug Administration; 2011. Available from: https://nedrug.mfds.go.kr/ eBook/access/ecatalog_sp.jsp? catimage $=\&$ callmode $=" \&$ Dir $=13$. Accessed November 29, 2019.

25. Martin JH, Norris R, Barras M, et al. Therapeutic monitoring of vancomycin in adult patients: a consensus review of the American Society of Health-System Pharmacists, the Infectious Diseases Society of America, and the Society Of Infectious Diseases Pharmacists. Clin Biochem Rev. 2010;31(1):21-24.

26. Schwartz GJ, Muñoz A, Schneider MF, et al. New equations to estimate GFR in children with CKD. J Am Soc Nephrol. 2009;20 (3):629-637. doi:10.1681/ASN.2008030287

27. Molitoris BA, Levin A, Warnock DG, et al. Improving outcomes of acute kidney injury: report of an initiative. Nat Clin Pract Nephrol. 2007;3(8):439-442. doi:10.1038/ncpneph0551

28. Stevens DL, Herr D, Lampiris H, et al. Linezolid versus vancomycin for the treatment of methicillin-resistant Staphylococcus aureus infections. Clin Infect Dis. 2002;34(11):1481-1490. doi:10.1086/340353

29. Weigelt J, Itani K, Stevens D, et al. Linezolid versus vancomycin in treatment of complicated skin and soft tissue infections. Antimicrob Agents Chemother. 2005;49(6):2260-2266. doi:10.1128/AAC.49.6.2 260-2266.2005

30. Itani KM, Dryden MS, Bhattacharyya $\mathrm{H}$, et al. Efficacy and safety of linezolid versus vancomycin for the treatment of complicated skin and soft-tissue infections proven to be caused by methicillin-resistant Staphylococcus aureus. Am J Surg. 2010;199(6):804-816. doi:10.1016/j.amjsurg.2009.08.045

31. Hidayat LK, Hsu DI, Quist R, et al. High-dose vancomycin therapy for methicillin-resistant Staphylococcus aureus infections: efficacy and toxicity. Arch Intern Med. 2006;166(19):2138-2144. doi:10.1001/archinte.166.19.2138

32. Lodise TP, McKinnon PS, Swiderski L, et al. Outcomes analysis of delayed antibiotic treatment for hospital-acquired Staphylococcus aureus bacteremia. Clin Infect Dis. 2003;36(11):1418-1423. doi:10.1086/375057

33. Frymoyer A, Hersh AL, Benet LZ, et al. Current recommended dosing of vancomycin for children with invasive methicillin-resistant Staphylococcus aureus infections is inadequate. Pediatr Infect Dis $J$. 2009;28(5):398-402. doi:10.1097/INF.0b013e3181906e40

34. Tetelbaum M, Finkelstein Y, Nava-Ocampo AA, et al. Back to basics: understanding drugs in children: pharmacokinetic maturation. Pediatr Rev. 2005;26:321-328. doi:10.1542/pir.26-9-321

35. Suggs DM. Pharmacokinetics in children: history, considerations, and applications. J Am Acad Nurse Pract. 2000;12:236-239. doi:10.1111/ j.1745-7599.2000.tb00188.x

36. Bartelink IH, Rademaker CM, Schobben AF, et al. Guidelines on pediatric dosing on the basis of developmental physiology and pharmacokinetic considerations. Clin Pharmacokinet. 2006;45 (11):1077-1097. doi:10.2165/00003088-200645110-00003

37. Elbarbry F. Vancomycin dosing and monitoring: critical evaluation of the current practice. Eur J Drug Metab Pharmacokinet. 2018;43 (3):259-268. doi:10.1007/s13318-017-0456-4

38. Paediatric, Formulary, Committee. British national formulary for children London: BMJ Group and Pharmaceutical Press; 2016-2017. Available from: http://www.lebpedsoc.org/doc/HIGHLIGHTS\%20FROM\%20THE \%20LITERATURE/bnf\%20book.pdf. Accessed November 29, 2019. 


\section{Publish your work in this journal}

Risk Management and Healthcare Policy is an international, peerreviewed, open access journal focusing on all aspects of public health, policy, and preventative measures to promote good health and improve morbidity and mortality in the population. The journal welcomes submitted papers covering original research, basic science, clinical \& epidemiological studies, reviews and evaluations, guidelines, expert opinion and commentary, case reports and extended reports. The manuscript management system is completely online and includes a very quick and fair peer-review system, which is all easy to use. Visit http://www.dovepress.com/testimonials.php to read real quotes from published authors.

Submit your manuscript here: https://www.dovepress.com/risk-management-and-healthcare-policy-journal 